\title{
BINARY CUCKOO SEARCH UNTUK OPTIMASI PORTOFOLIO DENGAN KENDALA CARDINALITY
}

\author{
Lilik Muzdalifah \\ Program Studi Matematika FMIPA Universitas PGRI Ronggolawe Tuban \\ Jl. Manunggal No. 61 Tuban \\ moezdalif_ah@yahoo.co.id
}

\begin{abstract}
ABSTRAK
Cuckoo Search merupakan salah satu metode optimasi metaheuristik yang terinspirasi dari tingkah laku burung Cuckoo. Algoritma Cuckoo Search pertama kali dikembangkan oleh Yang dan Deb pada tahun 2009. Pada dasarnya algoritma ini dikembangkan untuk menyelesaikan masalah optimasi yang hanya melibatkan variabel kontinu (real). Akan tetapi, pada kenyataannya banyak masalah optimasi yang melibatkan tidak hanya variabel real, teapi juga variabel diskrit, bulat, dan biner. Masalah optimasi portofolio dengan kendala cardinality, yaitu permasalahan membentuk komposisi dari berbagai aset dalam portofolio sehingga didapatkan hasil yang optimal dengan cara memilih $k$ aset dari $n$ aset yang tersedia. Masalah optimasi portofolio dengan kendala cardinality melibatkan variabel real dan biner (0-1). Pada variabel biner, nol artinya aset tersebut tidak dipilih sedangkan satu artinya aset tersebut dipilih untuk dimasukkan ke dalam portofolio. Pada penelitian ini penulis memodifikasi algoritma Cuckoo Search sehingga mampu mengatasi masalah optimasi yang melibatkan variabel real dan biner, yang selanjutnya disebut algoritma Binary Cuckoo Search. Kemudian algoritma tersebut diterapkan pada masalah meminimumkan risiko (Minrisk) dan memaksimumkan return (Maxret) dengan memilih 20 saham dari 31 saham Hangseng. Hasil penelitian menunjukkan bahwa Binary Cuckoo Search merupakan algoritma yang handal untuk mengatasi masalah optimasi portofolio dengan kendala cardinality.
\end{abstract}

Kata Kunci: algoritma cockoosearch, binary cuckoo search, optimasi portofolio, cardinality

\begin{abstract}
Cuckoo Search is one of metaheuristic optimization method that inspired by the behavior of Cuckoo Bird. Cuckoo Search algorithm is developed by Yang and Deb, Firstly at 2009. Basically, this algorithm is developed to solve optimization problem that just include continue variable (real). However, in fact there are many optimization problems not only includes real variable but also discrete, integer, and binary variable. Portfolio optimization problem with cardinality constraint is a problem to set some assets composition in portfolio such that gained optimal solution, by choosing $k$ assets from $n$ available assets. Portfolio optimization problem with cardinality constraint include real and binary (0-1) variables. In binary, zero means the asset is not chosen and one means the asset is chosen to be portfolio input. In this paper, the researcher modify Cuckoo Search algorithm such that is able to handle optimization problem with real and binary variable, called Binary Cuckoo Search Algorithm. Hereafter, that algorithm is applied to risk minimization and return maximization problem by choosing 20 assets from 31 Hangseng assets. This paper result shows that Binary Cuckoo Search is reliable algorithm to handle portfolio optimization problem with cardinality constraint.
\end{abstract}

Key Words: cuckoo search algorithm, binary cuckoo search, portfolio optimization, cardinality 


\section{Pendahuluan}

Cuckoo Search merupakan salah satu metode metaheuristik. Cuckoo Search terinspirasi dari perilaku unik burung Cuckoo. Yang dan Deb (2009) pertama kali mengembangkan metode ini dengan menggunakan asumsi:

a. Setiap burung Cuckoo hanya meletakkan satu telur pada satu waktu dan meletakkannya pada sarang burung lain yang dipilih secara acak.

b. Sarang terbaik dengan telur berkualitas tinggi (solusi), akan lolos menuju generasi selanjutnya.

c. Banyaknya sarang yang tersedia tetap, dan peluang telur burung Cuckoo ditemukan oleh burung yang menjadi sasaran parasitnya adalah $P a \in[0,1]$. Jika telur burung Cuckoo ditemukan, maka burung pemilik sarang akan meninggalkan sarangnya dan membuat sarang baru.

Dalam hal ini, telur pada sarang burung yang menjadi sasaran parasit burung Cuckoo merepresentasikan suatu solusi. Telur burung Cuckoo yang berkualitas tinggi kemudian akan menjadi solusi baru, yang akan menggantikan solusi yang kurang baik dalam sarang tersebut.

Algoritma dasar dari Cuckoo Searchdisajikan seperti pada gambar 1 (Yang 2010, Yang dan Deb 2009).

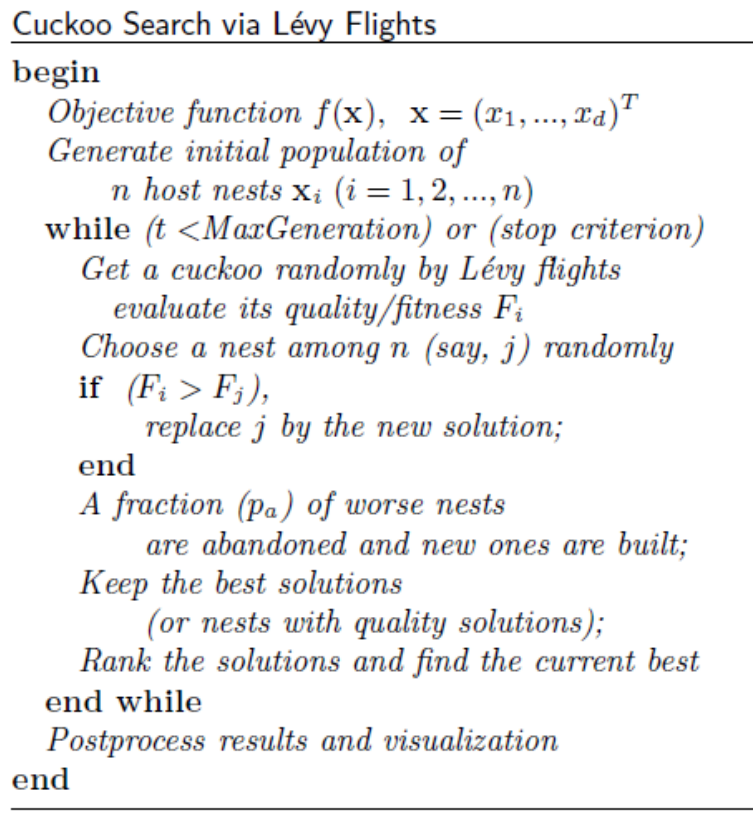

Gambar 1. Algoritma Cuckoo Search

Algoritma tersebut dikombinasikan dengan Lévy Flight, yaitu random walk dengan langkah acak yang berdistribusi Lévy. Solusi baru $x^{(t+1)}$, untuk cuckooi, dibangkitkan dengan Lévy Flight,

$$
x^{(t+1)}=x^{(t)}+\alpha \bigoplus \operatorname{Lévy}(\lambda)
$$

dimana $\alpha>0$ adalah panjang langkah yang berkaitan dengan skala permasalahan (bisa digunakan $\alpha=1$ ) dan $\oplus$ merupakan perkalian entrywise. Dalam masalah ini digunakan panjang langkah, step, yang mengikuti algoritma mantegna,

$$
\begin{gathered}
\text { step }=\frac{u}{|v|^{1 / \beta}}, 0<\beta \leq 2 \\
u \sim N\left(0, \sigma_{u}\right), \quad v \sim N\left(0, \sigma_{v}\right) \\
\sigma_{u}=\left\{\frac{\Gamma(1+\beta) \sin (\pi \beta / 2)}{\Gamma[(1+\beta) / 2] \beta 2^{(\beta-1) / 2}}\right\}^{1 / \beta} \\
\sigma_{v}=1
\end{gathered}
$$


Persamaan (1) adalah persamaan stokastik untuk random walk. Random walk dengan Lévy Flighttelah terbukti efisien dalam mengeksplorasi daerah pencarian solusi (Yang dan Deb 2009).

Portofolio merupakan kumpulan investasi yang dimiliki oleh institusi atau perorangan. Masing-masing investasi memiliki imbal hasil (return) dan risiko yang berbeda. Masalah optimasi portofolio merupakan permasalahan membentuk komposisi dari berbagai aset dalam portofolio sehingga didapatkan hasil yang optimal. Markowitz (1952) telah mengembangkan teori portofolio modern yang melibatkan masalah memaksimumkan return (Maxret) dan meminimumkan risiko (Minrisk). Suatu portofolio disebut sebagai portofolio efisien jika portofolio tersebut menghasilkan return maksimum dengan risiko tertentu atau menghasilkan risiko minimum dengan target return tertentu.

Untuk keperluan monitoring dan kontrol, para investor membatasi banyaknya jenis aset dalam portofolionya. Mereka melakukan investasi hanya pada sejumlah $k$ aset dari $n$ aset yang tersedia. Sehingga perlu dilakukan pemilihan kombinasi $k$ aset yang membentuk portofolio optimal. Masalah inilah yang disebut sebagai masalah optimasi portofolio dengan kendala cardinality. Untuk masalahmeminimumkan risiko (Minrisk) dengan diberikan target return sebesar $R p$, masalah tersebut dirumuskan sebagai berikut

$$
\text { Min } V=\vec{y}^{T} Q \vec{y}
$$

Kendala

$$
\begin{aligned}
& \overrightarrow{\vec{r}}^{T} \vec{y}=R p \\
& \quad \vec{e}^{T} \vec{y}=1 \\
& \quad y_{\min } z_{i} \leq y_{i} \leq y_{\max } z_{i} \\
& i=1,2, \ldots, n \\
& z_{i} \in\{0,1\} \\
& \sum_{i=1}^{n} z_{i}=k
\end{aligned}
$$

Sedangkan masalah memaksimumkan return (Maxret) dengan risiko yang berani diterima sebesar $V a$, dirumuskan sebagai berikut

$$
\operatorname{Min} R=-\overrightarrow{\vec{r}}^{T} \vec{y}
$$

Kendala

$$
\vec{y}^{T} Q \vec{y}=V a
$$

$$
\begin{aligned}
& \vec{e}^{T} \vec{y}=1 \\
& \quad y_{\min } z_{i} \leq y_{i} \leq y_{\max } z_{i} \\
& i=1,2, \ldots, n \\
& z_{i} \in\{0,1\} \\
& \sum_{i=1}^{n} z_{i}=k
\end{aligned}
$$

dimana $V$ dan $R$ secara berturut-turut adalah risiko dan return yang didapatkan. $\vec{y}=\left(\begin{array}{c}y_{1} \\ y_{2} \\ \vdots \\ y_{n}\end{array}\right)$ adalah proporsi investasimasing-masing aset $\left(y_{i} \in\right.$ 


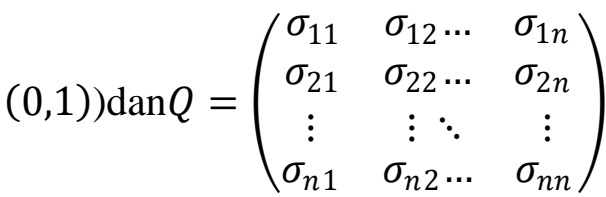

adalah matriks variansi-kovariansi.

$\overrightarrow{\vec{r}}=\left(\begin{array}{c}\bar{r}_{1} \\ \bar{r}_{2} \\ \vdots \\ \bar{r}_{n}\end{array}\right)$ merupakan mean return

dari masing-masing aset. Sedangkan

$\vec{e}=\left(\begin{array}{c}1 \\ 1 \\ \vdots \\ 1\end{array}\right)$ adalah matriks satuan. $y_{\min }$ dan

$y_{\text {max }}$ merupakan batas bawah dan batas atas proporsi investasi dan $z_{i} \in\{0,1\}$ adalah variabel biner yang menyatakan suatu aset dipilih atau tidak untuk dimasukkan ke dalam portofolio.

Masalah (6) dan (7) dapat diselesaikan dengan cara mengubahnya menjadi masalah optimasi tanpa kendala, yaitu dengan menggunakan fungsi penalti. Fungsi penalti yang akan diminimumkan menjadi

$$
\begin{gathered}
V=\vec{y}^{T} Q \vec{y}+\rho\left(\vec{e}^{T} \vec{y}-1\right)^{2} \\
+\rho\left(\frac{\overrightarrow{\vec{r}}^{T} \vec{y}}{R p}-1\right)^{2}+ \\
\rho\left(\vec{e}^{T} \vec{z}-k\right)^{2} \\
R=-\overrightarrow{\vec{r}}^{T} \vec{y}+\rho\left(\vec{e}^{T} \vec{y}-1\right)^{2} \\
+\rho\left(\frac{\vec{y}^{T} Q \vec{y}}{V a}-1\right)^{2}+ \\
\rho\left(\vec{e}^{T} \vec{z}-k\right)^{2}
\end{gathered}
$$

dimana $\rho$ adalah parameter penalti yang merupakan bilangan positif yang cukup besar.
Masalah (6)/(8) dan (7)/(9) merupakan masalah optimasi yang melibatkan variabel real $\left(y_{i}\right)$ dan biner $\left(z_{i}\right)$. Pada penelitian ini akan dilakukan modifikasi pada algoritma Cuckoo Search (Gambar 1) sehingga algoritma tersebut mampu mengatasi masalah optimasi yang melibatkan variabel real dan biner, selanjutnya disebut algoritma Binary Cuckoo Search. Kemudian algoritma tersebut diterapkan pada masalah (8) dan (9) dengan memilih 20 saham dari 31 saham Hangseng.

\section{Metode Penelitian}

Tujuan utama dari penelitian ini adalah untuk menyelesaikan masalah optimasi portofolio dengan kendala cardinality menggunakan algortma Binary Cuckoo Search. Data yang digunakan adalah 31 saham Hangseng, kemudian dipilih 20 saham untuk dimasukkan ke dalam portofolio $(k=$ 20). Data yang digunakan adalah data mingguan pada periode Maret 1992 September $199(2.44)$ (http://people.brunel.ac.uk/ mastjjb/jeb/o rlib/files/), dengan mean return pada tabel 1.

Tabel 1.Mean Return 31 Saham Hangseng

\begin{tabular}{cccc}
\hline $\begin{array}{c}\text { Saha } \\
\text { m }\end{array}$ & $\begin{array}{c}\text { Mean } \\
\text { Return }\end{array}$ & $\begin{array}{c}\text { Saha } \\
\text { m }\end{array}$ & $\begin{array}{c}\text { Mean } \\
\text { Return }\end{array}$ \\
\hline
\end{tabular}




\begin{tabular}{cccc}
\hline $\mathbf{1}$ & 0.001309 & 21 & 0.002699 \\
$\mathbf{2}$ & 0.004177 & 22 & 0.001879 \\
$\mathbf{3}$ & 0.001487 & 23 & 0.004656 \\
$\mathbf{4}$ & 0.004515 & 24 & 0.003842 \\
$\mathbf{5}$ & 0.010865 & 25 & 0.002690 \\
$\mathbf{6}$ & 0.001759 & 26 & 0.004793 \\
$\mathbf{7}$ & 0.002594 & 27 & 0.003286 \\
$\mathbf{8}$ & 0.004950 & 28 & 0.002338 \\
$\mathbf{9}$ & 0.007115 & 29 & 0.005817 \\
$\mathbf{1 0}$ & 0.003186 & 30 & 0.001993 \\
$\mathbf{1 1}$ & 0.002093 & 31 & 0.002380 \\
$\mathbf{1 2}$ & 0.005202 & & \\
$\mathbf{1 3}$ & 0.004489 & & \\
$\mathbf{1 4}$ & 0.003642 & & \\
$\mathbf{1 5}$ & 0.003960 & & \\
$\mathbf{1 6}$ & 0.000141 & & \\
$\mathbf{1 7}$ & 0.000282 & & \\
$\mathbf{1 8}$ & 0.000392 & & \\
$\mathbf{1 9}$ & 0.005294 & & \\
$\mathbf{2 0}$ & 0.004801 & & \\
\hline
\end{tabular}

Data tersebut dimodelkan dalam portofolio Markowitz kemudian diolah untuk dicari solusi optimumnya menggunakan alat bantu Matlab R2013a dengan algoritma BinaryCuckoo Search. Data diproses dengan melakukan running sebanyak 20 kali dan solusi yang diambil adalah solusi terbaik (optimum).

Algoritma Binary Cuckoo Searchpada dasarnya tidak mengurangi atau menghilangkan sifat dasar dari Cuckoo Search. Asumsi dan langkah yang digunakan masih sama dengan asumsi dan langkah dari algoritma Cuckoo Search. Hanya saja, variabel yang digunakan tidak hanya variabel real tetapi juga variabel biner, $\left[y_{i}, z_{i}\right]$. Variabel biner $\left(z_{i}\right)$ didapatkan dengan cara mengkonversi variabel real $\left(y_{i}\right)$ menggunakan fungsi sigmoid yang didefinisikan sebagai berikut,

$$
z_{i}= \begin{cases}1 & \text { jika sig }\left(y_{i}\right) \geq 0,5 \\ 0 & \text { jika yang lainnya }\end{cases}
$$

dengan

$$
\operatorname{sig}(y)=\frac{1}{\left(1+e^{-y}\right)}
$$

(Hongqing Zheng, Yongquan Zhou , Sucai He, Xinxin Ouyang 2012, Yanhong Feng, Ke Jia, dan Yichao He 2014). Kriteria pemberhentian yang digunakan adalah maximum generation(iterasi maksimum) dan kriteria pemberhentian Cauchy. Kriteria pemberhentian Cauchy digunakan untuk mengontrol efisiensi waktu dalam pencarian solusi terbaik, tanpa menunggu sampai iterasi maksimum berakhir. Kriteria pemberhentian inidilakukan setelah iterasi mencapai setengah dari iterasi maksimum dan dilakukan pengecekan selama 50 iterasi secara berturut-turut. Dalam penelitian ini, digunakan asumsi bahwa jika selama 50 iterasi secara berturut-turut tidak ada perubahan solusi $\left(\delta_{i} \leq\right.$ eps, $\left.i=k, k+1, \ldots, k+49\right)$ maka proses selesai.

dimana,

$$
\begin{gathered}
\delta_{i}=\mid \text { fbest }_{i}-\text { fbest }_{i-1} \mid, i \\
=k: k+49
\end{gathered}
$$

$k$ adalah indeks iterasi yang dimulai dari $\frac{1}{2}$ iterasi $\max +50$, fbest $_{i}$ adalah nilai fungsi solusi terbaik pada iterasi ke- $i$, dan eps adalah batas toleransi pemberhentian 
(biasanya dipilih $10^{-12}$ ). Algoritma

Binary Cuckoo Search dirumuskan sebagai berikut,

\section{Begin}

Fungsi objektif $f(y, z), \quad y=$ $\left(y_{1}, \ldots, y_{d}\right)^{T}, z=\left(z_{1}, \ldots, z_{d}\right)^{T}$

Bangkitkan populasi awal sebanyak $n$ sarang $\left[y_{i}, z_{i}\right], i=1,2, \ldots, n$

while $(t<$ MaxGeneration $)$ dan

(kriteria pemberhentian Cauchy)

Bangkitkan sarang baru dengan

Lévy flight dan evaluasi

kualitas/fitness-nya, $F_{i}$

Pilih satu sarang dari $n$ sarang yang ada secara acak (katakan, $j$ )

if $\left(F_{i}<F_{j}\right)$

ganti $j$ dengan solusi baru

end

Sarang terburuk dengan peluang ditemukan $>P a \in[0,1]$, digantikan dengan sarang baru

Simpan solusi baru

Urutkan semua solusi dan tentukan solusi terbaik saat ini.

\section{end while}

Hasil dan visualisasi

\section{End}

\section{Hasil dan Pembahasan}

Pada Bab ini akan dibahas mengenai hasil penerapan Binary Cuckoo Search untuk masalah optimasi portofolio dengan kendala cardinality, yaitu masalah (8) dan (9). Adapun input parameter yang digunakan adalah, $d=31, n=10 d$, $P a=0.1, \quad N_{\text {itermax }}=200000, \quad$ eps $=$ $10^{-12}, \quad r h o=10^{2}$, dan $m u=10^{5}$. Untuk masalah Minrisk, digunakan target return, $R p=0.006$. Sedangkan untuk masalah Maxret, besar risiko yang berani diterima, $V a=0.0025$. Syarat batas minimum tiap saham adalah $y_{\min }=$ 0.0075 dan syarat batas maksimum tiap saham adalah $y_{\max }=1$. Dari 31 saham Hangseng tersebut akan dipilih 20 saham $(k=20)$.

Masalah optimasi portofolio seperti yang didefinisikan pada persamaan (8) dan (9), dikerjakan menggunakan algoritma Binary Cuckoo Search dan setelah dilakukan proses running sebanyak 20 kali, didapatkan hasil terbaik sebagai berikut,

Tabel 2. Hasil Minrisk dan Maxret dengan KendalaCardinalitydipilih 20

Saham dari 31 saham Hangseng

\begin{tabular}{|c|c|c|c|c|}
\hline \multirow[t]{2}{*}{$\begin{array}{c}\text { Saha } \\
\text { m }\end{array}$} & \multicolumn{2}{|c|}{$\begin{array}{c}\text { Minrisk dengan } \\
\text { kendala } \\
\text { cardinality } \\
\text { Pers. }(\mathbf{2 . 5 5}) \\
\end{array}$} & \multicolumn{2}{|c|}{$\begin{array}{c}\text { Maxret dengan } \\
\text { kendala } \\
\text { cardinality } \\
\text { Pers. }(2.56) \\
\end{array}$} \\
\hline & $y_{i}$ & $z_{i}$ & $y_{i}$ & $z_{i}$ \\
\hline 1 & 0.0000 & 0 & 0.0075 & 1 \\
\hline 2 & 0.0075 & 1 & 0.0000 & 0 \\
\hline 3 & 0.0075 & 1 & 0.0000 & 0 \\
\hline 4 & 0.0075 & 1 & 0.0000 & 0 \\
\hline 5 & 0.2561 & 1 & 0.4477 & 1 \\
\hline 6 & 0.0000 & 0 & 0.0000 & 0 \\
\hline 7 & 0.0000 & 0 & 0.0075 & 1 \\
\hline 8 & 0.0223 & 1 & 0.0000 & 0 \\
\hline 9 & 0.0794 & 1 & 0.0466 & 1 \\
\hline 10 & 0.0075 & 1 & 0.0075 & 1 \\
\hline 11 & 0.0000 & 0 & 0.0000 & 0 \\
\hline 12 & 0.0000 & 0 & 0.0075 & 1 \\
\hline 13 & 0.0619 & 1 & 0.0000 & 0 \\
\hline 14 & 0.0075 & 1 & 0.0075 & 1 \\
\hline 15 & 0.0727 & 1 & 0.0000 & 0 \\
\hline
\end{tabular}




\begin{tabular}{|l|l|l|l|l|}
\hline 16 & 0.0000 & 0 & 0.0075 & 1 \\
17 & 0.0075 & 1 & 0.0075 & 1 \\
18 & 0.0075 & 1 & 0.0075 & 1 \\
19 & 0.0000 & 0 & 0.3576 & 1 \\
20 & 0.0075 & 1 & 0.0075 & 1 \\
21 & 0.0075 & 1 & 0.0000 & 0 \\
22 & 0.0000 & 0 & 0.0075 & 1 \\
23 & 0.0000 & 0 & 0.0000 & 0 \\
24 & 0.0000 & 0 & 0.0075 & 1 \\
25 & 0.0075 & 1 & 0.0075 & 1 \\
26 & 0.1446 & 1 & 0.0125 & 1 \\
27 & 0.0075 & 1 & 0.0075 & 1 \\
28 & 0.1326 & 1 & 0.0075 & 1 \\
29 & 0.1165 & 1 & 0.0231 & 1 \\
30 & 0.0315 & 1 & 0.0075 & 1 \\
31 & 0.0000 & 0 & 0.0000 & 0 \\
\hline \multicolumn{7}{|l|}{$V=0.0010$} & \multicolumn{3}{|c|}{$R=0.0076$} \\
\hline
\end{tabular}

Dari hasil masalah Minrisk dan Maxretdengan kendala cardinality, 20 saham yang terpilih untuk dimasukkan ke dalam portofolio adalah saham dengan nilai $z_{i}=1$, dengan proporsi saham yang akan diinvestasikan sebesar $y_{i}$. Risiko dan return yang didapatkan secara berturut-turut adalah $V=0.0010$ dan $R=0.0076$. Dari tabel 2 terlihat bahwa proporsi investasi sudah memenuhi kendala yang diberikan, (1) Jumlah proporsi investasi semua saham adalah 1 , (2) ketika $z_{i}=1$, proporsi investasi selalu lebih dari batas bawah, $y_{\min }=$ 0.0075, dan kurang dari 1, (3) ketika $z_{i}=0$ maka tidak ada investasi untuk saham terkait, $y_{i}=0$, dan (4) tepat terpilih 20 saham yang membentuk portofolio optimum, $k=20$. Hal ini membuktikan bahwa Binary Cuckoo Search mampu menyelesaikan masalah optimasi portofolio dengan kendala cardinality dengan sangat baik.

Akan tetapi, penelitian ini hanya terbatas pada modifikasi algoritma Cuckoo Search menjadiBinary Cuckoo Search untuk kemudian diterapkan pada masalah optimasi portofolio dengan kendala cardinality. Solusi optimum yang didapatkan belum dibandingkan dengan solusi optimum dari penelitian lain dengan masalah optimasi yang sama dan algoritma berbeda. Hal ini dilakukan untuk membuktikan Binary Cuckoo Search lebih baik atau tidak lebih baik dari algoritma metaheuristik lain dalam menyelesaikan masalah optimasi portofolio dengan kendala cardinality.

\section{Kesimpulan}

Alhasil, algoritma Cuckoo Search yang pada dasarnya dikembangkan untuk menyelesaikan masalah optimasi yang hanya melibatkan variabel kontinu (real), dapat dimodifikasi untuk menyelesaikan masalah optimasi yang melibatkan variabel real dan biner, disebut algoritma Binary Cuckoo Search. Penerapan algoritma Binary Cuckoo Search untuk menyelesaikan masalah optimasi portofolio dengan kendala cardinality, memberikan hasil yang sangat baik. Dari 31 saham Hangseng terpilih tepat 20 saham yang membentuk portofolio optimum, dengan risiko dan return yang 
didapatkan secara berturut-turut adalah $V=0.0013$ dan $R=0.0128$.

Lebih lanjut, hasil dari penelitian ini perlu dibandingkan dengan hasil penelitian lain dengan masalah optimasi yang sama dan algoritma berbeda. Hal ini ditujukan untuk membandingkan kehandalan Binary Cuckoo Search dibandingkan dengan algoritma metaheuristik lainnya dalam mengatasi masalah optimasi tersebut. Selain itu, algoritma Binary Cuckoo Search juga diharapkan dapat diterapkan pada masalah optimasi lainnya yang melibatkan variabel real dan biner. Lebih jauh lagi, algoritma Cuckoo Search diharapkan dapat dimodifikasi untuk menyelesaikan berbagaimasalah optimasi dengan berbagai macam variabel lainnya.

\section{Pustaka}

Hongqing Zheng, Yongquan Zhou, Sucai He, Xinxin Ouyang. 2012. A Discrete Cuckoo Search Algorithm for Solving Knapsack Problems.Advances in information Sciences and Service Sciences(AISS), Vol. 4.
Markowitz, H. 1952. Portofolio Selection. The Journal of Finance,Vol. 7, pp. 77-91.

Yang, X. S. 2010. Nature-Inspired Metaheuristic Algorithms, Second Edition, United Kingdom: Luniver Press.

Yang, X. S. dan Deb, S. 2009. Cuckoo Search via Lévy Flights. Proceeding of World Congres on Nature and Biologically Inspired Computing (NaBIC 2009, India), IEEE Publications, USA, pp.210214.

Yanhong Feng, Ke Jia, dan Yichao He. 2014. An Improved Hybrid Encoding Cuckoo Search Algorithm for 0-1 Knapsack

Problems. The Journal of Computational Intelligence and Neuroscience,Vol. 2014, Article ID 970456, 9 pages.

http://people.brunel.ac.uk/ mastjjb/jeb/or lib/files/, Diakses pada tanggal8 April 2016, pukul 15.00 WIB 